\title{
Aerobic exercise combined with environmental enrichment improves spatial memory and enhances neuroligin 1 expression: an animal study
}

Faizah Abdullah Djawas, ${ }^{1,2}$ Sri Redjeki, ${ }^{3}$ Ria Kodariah, ${ }^{4}$ Neng Tine Kartinah ${ }^{3}$

pISSN: 0853-1773 • elSSN: 2252-8083 https://doi.org/10.13181/mji.v28i3.2109 Med J Indones. 2019;28:228-33

Received: October 14, 2017

Accepted: May 29, 2019

\section{Authors' affiliations:}

${ }^{1}$ Physiotherapy Study Program,

Vocational Education Program,

Universitas Indonesia, Depok, Indonesia,

${ }^{2}$ Master Program in Biomedical Sciences,

Faculty of Medicine, Universitas

Indonesia, Jakarta, Indonesia,

${ }^{3}$ Department of Medical Physiology,

Faculty of Medicine, Universitas

Indonesia, Jakarta, Indonesia,

${ }^{4}$ Department of Anatomical Pathology,

Faculty of Medicine, Universitas

Indonesia, Jakarta, Indonesia

Corresponding author:

Neng Tine Kartinah

Department of Medical Physiology,

Faculty of Medicine, Universitas

Indonesia, Jalan Salemba 6, Senen

Central Jakarta 10320, DKI Jakarta,

Indonesia

Tel/Fax: +62-21-31930366/+62-21-

31908824

E-mail: ntkalmuktabar@gmail.com

\begin{abstract}
BACKGROUND Numerous studies have revealed that aerobic exercise (AE) or environmental enrichment (EE) exert positive effects on the molecular, cellular, and structural changes responsible for functional plasticity. Therefore, this study was aimed to investigate whether the combination of $A E$ and $E E$ yields a greater effect on spatial memory and increases the expression of the adhesion molecule neuroligin 1 compared with either of the therapies alone.
\end{abstract}

METHODS Twenty 6-month-old male Wistar rats were randomly divided into four groups: (1) the control group (C), (2) the AE group, (3) the EE group, and (4) the AEEE group. Escape latency in a water-E-maze (WEM) task was used as a parameter to assess spatial memory function. Neuroligin 1 protein expression was examined via the immunohistochemistry (IHC) technique followed by IHC optical density (OD) score analysis of the CA1 hippocampal region.

RESULTS Data acquired from the WEM task show that escape latency progressively decreased over time in all groups. However, animals in the AE-EE group required less time to complete the task compared with those in the control, $\mathrm{AE}$, and $\mathrm{EE}$ groups. IHC $O D$ scores revealed that the combination of $A E$ and $E E$ caused the highest expression of neuroligin 1 in the $C A 1$ hippocampal region among the therapies studied. Statistical analysis indicated significant differences in OD score between the AE-EE and control, $A E$, and EE groups $(p \leq 0.001)$.

CONCLUSIONS The combination of AE and EE rats increased neuroligin 1 expression and improved the spatial memory of male Wistar rats compared with application of either therapy alone.

KEYWORDS aerobic exercise, neuroligin 1, neuroplasticity, spatial memory
Memory decline is associated with a decrease in neuroplasticity starting from early adulthood. ${ }^{1}$ Neuroplasticity is regulated and affected by various external stimuli, resulting in modification of the molecular, cellular, and structural changes responsible for functional plasticity. Emerging evidence suggests that an external stimulus, namely, environmental enrichment (EE), influences the development of the nervous system. Alterations in EE animals include increased levels of neurotrophic factors, enhanced hippocampal dendritic structural plasticity, and stimulated synaptic plasticity and neurogenesis, all of which contribute to spatial memory performance. ${ }^{2-4}$ Improvements in memory functions are also induced by aerobic exercise (AE) through modification of gene expression, enhanced synaptic protein expression and postsynaptic structures, and increased synaptic transmission. ${ }^{5}$ Structural changes in the CA1 hippocampal region have been observed to lead to improvements in 
spatial memory function in rats subjected to lowintensity treadmill training. ${ }^{6}$ Recent studies have shown that synaptic plasticity is regulated by interactions between presynaptic and postsynaptic neurons, including cell-adhesion molecules, scaffolding proteins, and the synaptic vesicle machinery. Neuroligin 1, a postsynaptic cell-adhesion molecule that binds to the presynaptic neurexin and postsynaptic density 95 protein (PSD-95), plays an important role in signal transduction and synaptic formation and maturation, which are essential for cognitive function. $4,5,7$ Thus, the aim of this study was to investigate whether the combination of $A E$ and EE provides a greater effect on spatial memory than either of the therapies alone.

\section{METHODS}

The study design and methods was approved by the Ethics Committee of the Faculty of Medicine Universitas Indonesia (No. 849/UN2.F1/ETIK/2016). This study was conducted from August 2016 until February 2017. Animal care and surgical procedures were performed at standardized place in Balai Penelitian dan Pengembangan Kesehatan RI (Jakarta), protein analysis was done at the Immunopathology Laboratory, Department of Anatomical Pathology, Faculty of Medicine, Universitas Indonesia, and tissue analysis and imaging were conducted at the Pharmacokinetic Laboratory, Department of Pharmacology and Therapeutic, Faculty of Medicine, Universitas Indonesia.

\section{Subjects}

Twenty 6-month-old male Wistar rats were randomly assigned to one of four groups, namely: (1) the control group $(n=5),(2)$ the AE group (rats submitted to $A E ; n=5$ ), (3) the $E E$ group: (rats housed in an EE cage; $n=5$ ), and (4) the AE-EE group (combination of $A E$ and $E E ; n=5$ ). The animals were housed at $25 \pm 1{ }^{\circ} \mathrm{C}$ with a 12 hours/12 hours light/ dark cycle and unlimited access to food and water throughout the experiment.

\section{Exercise protocol}

Light-intensity AE was provided in this experiment by using an animal treadmill. Prior to the experiment, subjects underwent a familiarization period, which consisted of running on the treadmill for $10 \mathrm{~min}$ for five consecutive days at a rate of $10 \mathrm{~m} / \mathrm{min}$. The exercise protocol was given 5 days a week for 6 weeks (Monday to Friday). In each session, the animals were allowed to warm up for $5 \mathrm{~min}$ by running at speed of $10 \mathrm{~m} / \mathrm{min}$; the training speed and duration were set to $20 \mathrm{~m} / \mathrm{min}$ and $30 \mathrm{~min}$, respectively. ${ }^{8,9}$

\section{Environmental enrichment (EE) cage}

EE refers to housing conditions under which laboratory animals experience higher levels of sensory, motor, social, and cognitive stimuli compared with standard laboratory housing conditions. ${ }^{4}$ EE cage adapted from the Marlau ${ }^{\mathrm{TM}}$ cage protocol with slight modifications were used in this study. The size of the cage is: length $=800 \mathrm{~mm} \times$ width $=600 \mathrm{~mm} \times$ height $=510 \mathrm{~mm}$ and consisted of two floors. The ground floor was divided into a feeding area (G1) and a play area (G2) connected by a oneway door from $\mathrm{G}_{1}$ to $\mathrm{G}_{2}$. The play area was equipped with water bottles, a white rectangular house, and three running wheels in pink, blue, and yellow. G2 was connected to the upper floor, in which the maze was placed, through a climbing ladder. The second floor was also connected to $\mathrm{G}_{1}$ (the other side of the cage) through a sliding tunnel. ${ }^{10}$

\section{Housing protocol}

Prior to the study, subjects in the EE and AEEE groups were kept in an enriched environment for 1 week for familiarization with the environment (without changing the maze configuration). After the familiarization period, the animals were kept in their respective housing throughout the experiment. Standardization of novelty and cognitive stimulation were ensured by changing the maze configuration thrice a week on Monday, Wednesday, and Friday using six mazes (series $A-F$ ), each consisting of two different configurations. ${ }^{10}$ Rats in the control group were kept in isolation cages, while rats in the $\mathrm{AE}$ group were kept in regular rat cages.

\section{Water-E-maze (WEM) task}

For this study, the WEM apparatus which evaluates spatial learning and memory were used. The WEM device is an E-shaped glass pool filled with water. It consists of a U-shaped main trench and three trenches branching perpendicularly to the main trench, two edge trenches ( $\mathrm{ti}$ ), and the middle trench (ta). The length of the main trench was $1.25 \mathrm{~m}$, the 
middle trench measured $35 \mathrm{~cm}$, and the edge trenches measured $25 \mathrm{~cm}$ each. The height and width of each trench were 60 and $25 \mathrm{~cm}$, respectively. The $M$ point in the middle trench was the starting point of the learning and memory test and a ladder was laid in one of the edge trenches as a goal $(G)$ for the animal on their efforts to escape from the water. Escape latency (in seconds) was recorded in this study. ${ }^{8}$

During the training phase, the rats were exposed to the WEM apparatus 5 days per week. Each rat randomly explored the device for no longer than $180 \mathrm{sec}$. If the rats did not find the ladder, they were gently guided to it and allowed to remain on it for $10 \mathrm{sec}$ to help them become familiar with the WEM environment. For the spatial learning test, the rats were subjected to three trials without an interval and allowed $120 \mathrm{sec}$ for each trial to reach the ladder. ${ }^{8,9}$ The test was performed on all groups at weeks $0,2,4$, and 6 .

\section{Immunostaining}

Paraffin sections $(4 \mu \mathrm{m})$ of the hippocampus of all subjects were subjected to immunohistochemistry (IHC) to identify expression levels of neuroligin 1. Hippocampal sections were incubated with antineuroligin 1 antibody (Santa Cruz Biotechnology, Inc.) at 1:750 dilution. The negative control was treated as described above except that the antibody against antineuroligin 1 antibody was omitted. Cell Purkinje which is located in rat cerebellum is used as positive control. Horseradish peroxidase-based staining systems (antimouse, rat, rabbit, and guinea pig) from Biogear were used as secondary antibodies.

\section{Imaging}

Images were captured as five large fields of view by a binocular light microscope (Leica DM500) equipped with a built-in camera (Leica ICC50 HD) at 400 magnification in various target areas of the CA1 hippocampal region. Protein expression was analyzed via an open-source plugin called Immunohistochemistry Profiler, which is compatible with ImageJ software, for IHC analysis using color deconvolution and computerized pixel profiling to enable assignment of an automated score to each image.

\section{IHC optical density (OD) score}

Although IHC Profiler counts a pixel intensity and computes its score automatically, the final score is

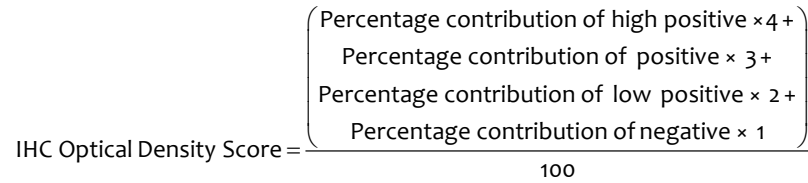

shown in a semiquantitative manner (high positive, positive, low positive, or negative). The following algebraic formula is used to calculate the IHC OD score (from 1 to 4 ) of the IHC images. ${ }^{11}$

\section{Statistical analysis}

Statistical analysis were performed using SPSS software, version 22 (IBM), and graphs were drawn using GraphPad Prism. Average escape latency data within a group between week 0 and weeks 2, 4, and 6 were analyzed using paired t-test, while IHC OD data between groups were analyzed using the Kruskal-Wallis test followed by Mann-Whitney posthoc analysis. In this study, $p<0.05$ was considered statistically significant.

\section{RESULTS}

\section{Water E-maze (WEM) task}

The results of the memory spatial test using the WEM device are presented in Figure 1. Figure 1 illustrates a reduction in escape latency in the control group, although paired t-test revealed no significant difference in escape latencies between week o (18.5 [3.9]) and weeks 2 (16.6 [4.4]; $p=0.578), 4$ (13.3 [8.2]; $p=0.233)$, and 6 (15.7 [11.4]; $p=0.368)$. Moreover, the data show that the escape latency of rats in the control group increased at week 6 compared with that at week 4 (Figure 1). Paired t-test showed significant differences in escape latency in the aerobic group between weeks 0 (18.9 [4.0]) and 4 (10.9 [4.0]; $p=0.049)$ and between weeks 0 and 6 (7.1 [4.1]; $p=0.003)$. No significant difference in escape latency was observed in the $\mathrm{EE}$ group between week $0(17.5[10.2])$ and weeks $2(9.2[5.6] ; p=0.159)$ and 4 (8.9 [5.1]; $p=0.082$ ); however, a significant difference in escape latency between weeks 0 and 6 (5.9 [1.4]; $p=0.020)$ was found. Statistical analysis of the AE-EE group results showed significant differences in escape latencies between weeks 0 (19.8 [11.3]) and 4 (7.1 [3.1]; $p=0.041)$ and between weeks 0 and 6 (4.6 [1.6]; $p<0.001)$. Altogether, these data suggest that the escape latency progressively decreases with time in all groups, indicating spatial 
Figure 1. Escape latency during the Water E-waze (WEM) task. Each point represents the block mean (SD) of the latency indicate better performance. Among the groups studied, the AEEE group $(n=5)$ exhibited the best performance throughout the experiment. $\mathrm{AE}=$ aerobic exercise; $\mathrm{EE}=$ =nvironmental enrichment WEM task. Lower numbers of escape

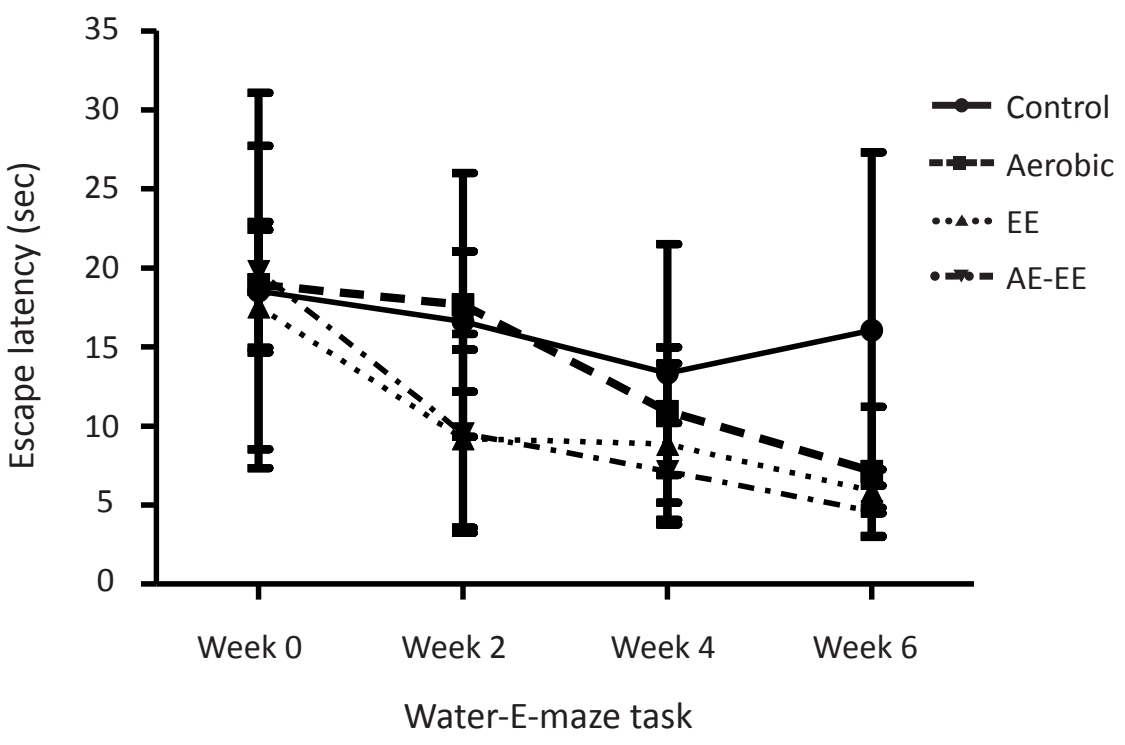

rats in the control group (1.3 [0.11]), the aerobic group (1.4 [0.15]), and the EE group (1.4 [0.24]), as revealed in Figure 3.

\section{Neuroligin 1 protein expression}

To identify the expression of neuroligin 1, IHC staining of this protein was carried out on pyramidal cells of the CA1 hippocampal area. As shown in Figure 2, the AE-EE group revealed denser IHC expression than the other groups. The IHC OD scores of rats in the AE-EE group (1.6 [0.09]) were higher than those of

\section{DISCUSSION}

Stored information related to the environment and spatial orientation was needed by the rats to find the ladder in the WEM device. The decrease in average escape latency in the WEM task over-time showed learning and spatial memory formation in the animals. Deterioration in the spatial memory test
\end{abstract}
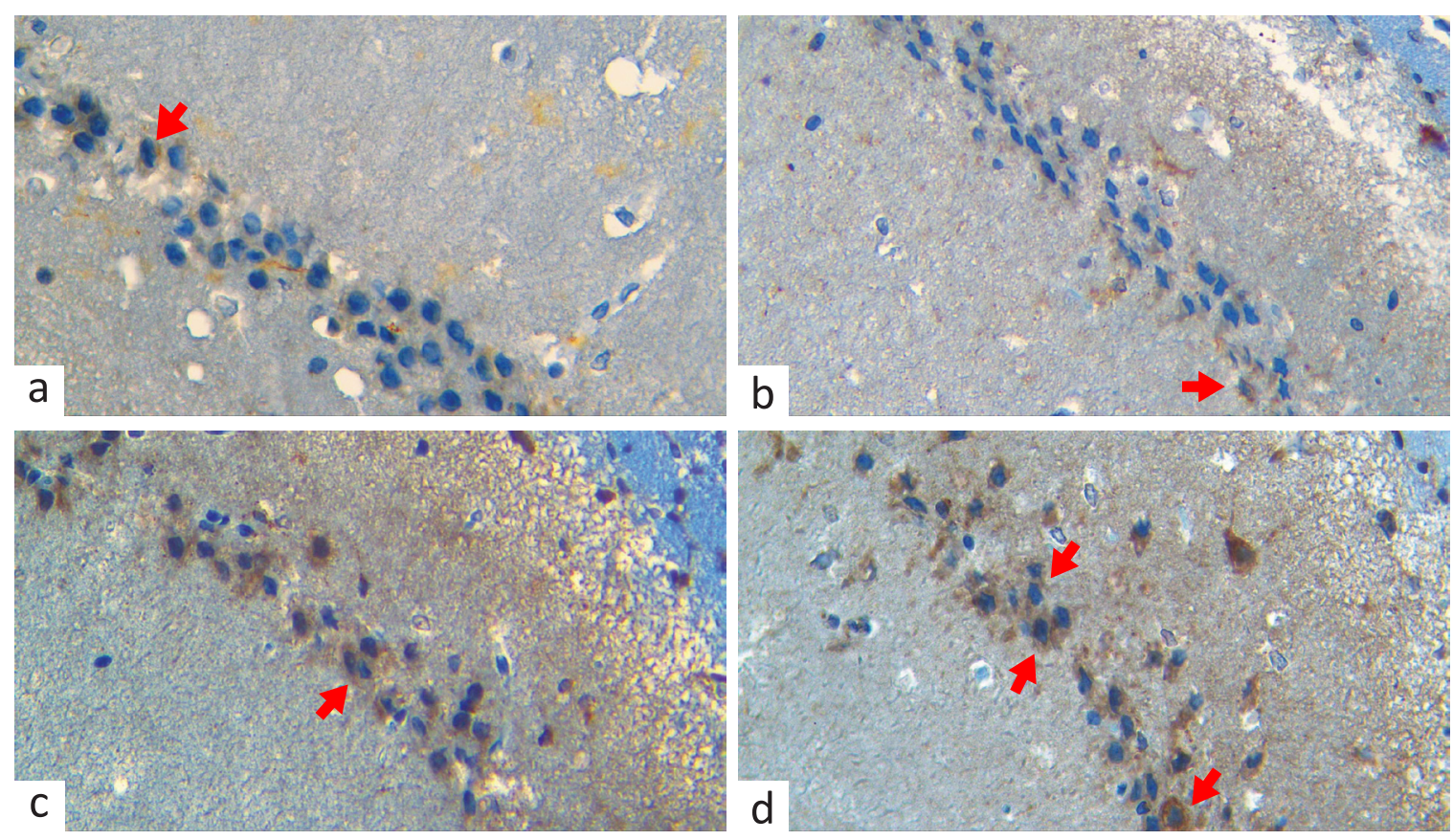

Figure 2. Expression of neuroligin 1 (red arrow) in the CA1 hippocampal region after 6 weeks of treatment: (a) control group; (b) AE group; (c) EE group; and (d) combination of AE-EE group. AE=aerobic exercise; EE=environmental enrichment 


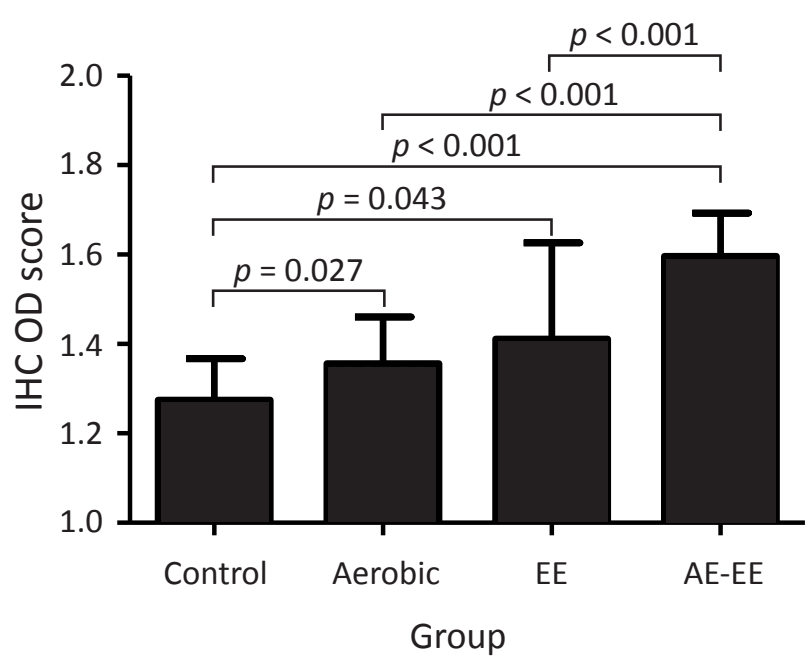

Figure 3. Neuroligin 1 protein immunostaining determined from the mean of IHC OD scores in the CA1 hippocampal region. Significant differences were determined by the Kruskal-Wallis test followed by the Mann-Whitney posthoc test. IHC=immunohistochemistry; $O D=$ optical density; $\mathrm{EE}=$ environmental enrichment; $\mathrm{AE}=$ aerobic exercise

of rats in the control group was assumed to be due to the placement of rats in the isolation cage because social isolation affects cognition and disrupts spatial memory. ${ }^{12,13}$

Using the WEM protocol, the rats from the AEEE group showed reduced escape latency over time and performed better than the other groups in completing the spatial memory task. These results indicate that the combination of $\mathrm{AE}$ and $\mathrm{EE}$ has a great impact on spatial memory in experimental animals. Various studies employing the Morris water maze, the $\mathrm{Y}$-maze, and the radial arm maze have demonstrated the role of $A E$ in facilitating structural and hippocampus-dependent spatial memory. 3,6,9 Similar results obtained from previous studies exposing rodents to an enriched environment with a variety of novel, cognitively challenging, and multimodal activities suggest that EE exerts protective effects against age-related cognitive decline and improves hippocampus-dependent learning and memory. ${ }^{4}$

Both $A E$ and $E E$ have been reported to increase several pre- and post-synaptic proteins involved in the formation of synapses in the rat hippocampus. Synaptic formation is induced by interactions between presynaptic and postsynaptic neurons, including cell-adhesion molecules, scaffolding proteins, and proteins associated with the synaptic vesicle machinery, such as synaptophysin, PSD95, neuroligin 1 , and $\beta$-neurexin. ${ }^{5,14,15}$ Physical exercise using a treadmill is believed to facilitate synaptogenesis through increased regulation of neuroligin 1 in the hippocampus. ${ }^{5}$ Neuroligin 1 interacts with its presynaptic partner neurexin to promote synapse development, structural stability, and plasticity. ${ }^{16,17}$ Its intracellular tail binds to PSD-95, a protein found in the postsynaptic sites of excitatory synapses. The interaction of PSD-95 and neuroligin 1 has been proposed to accelerate the maturation of synapses and strengthen its connections. ${ }^{17,18}$ Studies also show that $A E$ increases cell proliferation, neuron differentiation, neurogenesis, and cell survival, leading to improvements in synaptic plasticity. 3,6,9

The effect of $\mathrm{EE}$ on neuroligin 1 expression is unknown. Indeed, the results of this study may initiate future studies on the role of neuroligin 1 in functional excitatory synaptic formation. ${ }^{16,19-21}$ At the cellular level, application of EE increases dendritic branches, synaptogenesis, and neurogenesis in the hippocampus.22 Changes to this morphology are supported by changes in gene expression, especially those related to synapse function and neuroplasticity. ${ }^{4}$ These facts may represent a mechanism underlying the beneficial effect of $E E$ on neuroligin 1, which enhances brain function by improving learning, memory, and cognition. Taken together, AE and EE appear to increase neuroplasticity differently. AE increased both cell proliferation and neurogenesis, while EE appeared to increase neurogenesis only without affecting cell proliferation. ${ }^{23}$

In conclusion, the combination of aerobic exercise combined with environmental enrichment improves spatial memory and enhances neuroligin 1 expression in 6-month-old male Wistar rats better than $\mathrm{AE}$ or $\mathrm{EE}$ alone.

Conflict of Interest

The authors affirm no conflict of interest in this study.

\section{Acknowledgment}

The authors would like to thank Mr. Sahrul for helping the animal care and Ms. Fitri for the technical assistance.

\section{Funding Sources}

This research was funded by the Directorate Research and Community Services Universitas Indonesia (DRPM UI) in grant of International Publication Indexed for the Final Assignments (PITTA) 2016.

\section{REFERENCES}

1. Salthouse TA. When does age-related cognitive decline begin? Neurobiol Aging. 2009;30(4):507-14. 
2. Horvath G, Kiss P, Nemeth J, Lelesz B, Tamas A, Reglodi D. Environmental enrichment increases PACAP levels in the CNS of adult rats. Neuro Endocrinol Lett. 2015;36(2):143-7.

3. Voss MW, Vivar C, Kramer AF, van Praag H. Bridging animal and human models of exercise-induced brain plasticity. Trends Cogn Sci. 2013;17(10):525-44.

4. Kondo M. Molecular mechanisms of experience-dependent structural and functional plasticity in the brain. Anat Sci Int. 2017;92(1):1-17.

5. Fang ZH, Lee CH, Seo MK, Cho H, Lee JG, Lee BJ, et al. Effect of treadmill exercise on the BDNF-mediated pathway in the hippocampus of stressed rats. Neurosci Res. 2013;76(4):187-94.

6. Shih PC, Yang YR, Wang RY. Effects of exercise intensity on spatial memory performance and hippocampal synaptic plasticity in transient brain ischemic rats. PLoS One. 2013;8(10):e78163.

7. Schapitz IU, Behrend B, Pechmann Y, Lappe-Siefke C, Kneussel SJ, Wallace KE, et al. Neuroligin 1 is dynamically exchanged at postsynaptic sites. J Neurosci. 2010;30(38):12733-44.

8. Furqaani AR. Pengaruh latihan fisik terhadap kemampuan belajar dan memori serta kadar serotonin pada hipokampus tikus (Rattus novergicus) galur wistar jantan dewasa [thesis] Jakarta (Indonesia): Universitas Indonesia; 2013. Indonesian.

9. Cassilhas RC, Lee KS, Fernandes J, Oliveira MG, Tufik S, Meeusen R, et al. Spatial memory is improved by aerobic and resistance exercise through divergent molecular mechanisms. Neuroscience. 2012;202:309-17.

10. Fares RP, Kouchi H, Bezin L. Standardized environmental enrichment for rodents in Marlau cage. 2012 [cited 2016]. Available from: http://dx.doi.org/10.1038/protex.2012.036.

11. Seyed Jafari SM, Hunger RE. IHC optical density score: a new practical method for quantitative immunohistochemistry image analysis. Appl Immunohistochem Mol Morphol. 2017;25(1):e12e3.

12. Makinodan M, Rosen KM, Ito S, Corfas G. A critical period for social experience-dependent oligodendrocyte maturation and myelination. Science. 2012;337(6100):1357-60.

13. Pereda-Pérez I, Popović N, Otalora BB, Popović M, Madrid JA,
Rol MA, et al. Long-term social isolation in the adulthood results in CA1 shrinkage and cognitive impairment. Neurobiology Learn Mem. 2013;106:31-9.

14. Fischer A. Environmental enrichment as a method to improve cognitive function. What can we learn from animal models? Neuroimage. 2016;131:42-7.

15. Nithianantharajah J, Levis H, Murphy M. Environmental enrichment results in cortical and subcortical changes in levels of synaptophysin and PSD-95 proteins. Neurobiol Learn Mem. 2004;81(3):200-10.

16. Brito-Moreira J, Lourenco MV, Oliveira MM, Ribeiro FC, Ledo $J H$, Diniz LP, et al. Interaction of amyloid- $\beta(A \beta)$ oligomers with neurexin $2 \alpha$ and neuroligin 1 mediates synapse damage and memory loss in mice. Journal Biol Chem. 2017;292(18):7327-37.

17. Heine M, Thoumine O, Mondin M, Tessier B, Giannone G, Choquet D. Activity-independent and subunit-specific recruitment of functional AMPA receptors at neurexin/neuroligin contacts. Proc Natl Acad Sci U S A. 2008;105(52):20947-52.

18. El-Husseini AE, Schnell E, Chetkovich DM, Nicoll RA, Bredt DS. PSD-95 involvement in maturation of excitatory synapses. Science. 2000;290(5495):1364-8.

19. $\mathrm{Hu} \mathrm{X,} \mathrm{Luo} \mathrm{JH}, \mathrm{Xu} J$. The interplay between synaptic activity and neuroligin function in the CNS. BioMed Res Int. 2015;2015:498957.

20. Südhof TC. Neuroligins and neurexins link synaptic function to cognitive disease. Nature. 2008;455(7215):903-11.

21. Jiang M, Polepalli J, Chen LY, Zhang B, Südhof TC, Malenka RC. Conditional ablation of neuroligin-1 in CA1 pyramidal neurons blocks LTP by a cell-autonomous NMDA receptor-independent mechanism. Mol Psychiatry. 2017;22(3):375-83.

22. Kotloski RJ, Sutula TP. Environmental enrichment: evidence for an unexpected therapeutic influence. Exp Neurol. 2015;264:1216.

23. Olson AK, Eadie BD, Ernst C, Christie BR. Environmental enrichment and voluntary exercise massively increase neurogenesis in the adult hippocampus via dissociable pathways. Hippocampus. 2006;16(3):250-60. 